\title{
Single-Incision Laparoscopic Surgeries for Colorectal Diseases: Early Experiences of a Novel Surgical Method
}

\author{
Tomoki Makino, Jeffrey W. Milsom, and Sang W. Lee \\ Division of Colon and Rectal Surgery, New York Presbyterian Hospital, Weill Cornell Medical College, 525 East 68th Street, Box 172, \\ New York, NY 10021, USA \\ Correspondence should be addressed to Sang W. Lee, sal2013@med.cornell.edu
}

Received 3 November 2011; Revised 29 February 2012; Accepted 5 March 2012

Academic Editor: Boris Kirshtein

Copyright ( $(2012$ Tomoki Makino et al. This is an open access article distributed under the Creative Commons Attribution License, which permits unrestricted use, distribution, and reproduction in any medium, provided the original work is properly cited.

\begin{abstract}
Objectives. This paper aims to analyze the feasibility and safety of single-incision laparoscopic colectomy (SILC) and its potential benefits. Methods. Systematic review was performed for the years 1983-August 2011 to retrieve all relevant literature. A total of 21 studies with 477 patients undergoing SILC were selected. Results. Range of operative times and estimated blood losses were 75-229 min and 0-100 mL, respectively. Overall conversion rate was 5.9\% (28/477) and an additional laparoscopic port was used in 4.9\% (16/329) cases. Range of lymph node number for malignant cases was 12-24.6 and surgical margins were all negative. Overall mortality and morbidity rate was $0.4 \%$ (2/477) and $11.7 \%$ (43/368), respectively. The length of hospital stay (LOS) varied across reports (2.7-9.2 days). Among 6 case-matched studies, one showed less blood loss in SILC as compared to LAC and 2 showed shorter LOS after SILC versus HALC or LAC/HALC groups. In addition, one study reported maximum pain score on postoperative days 1 and 2 was lower in SILS compared to LAC and HALC. Conclusions. SILC procedure is feasible and safe when performed by surgeons highly skilled in laparoscopy. In spite of technical difficulties, there may be potential benefits associated with SILC over LAC/HALC.
\end{abstract}

\section{Introduction}

Recently, laparoscopic surgeries have been widely accepted as a treatment of colon diseases including colon cancer [13]. Most surgeons are convinced by the short time benefit of the laparoscopic approach in colorectal surgery, that is, early postoperative recovery, decreased postoperative pain, reduced pulmonary dysfunction, and shorter hospitalization [4-6]. Moreover, in oncological terms, it has also been shown to be safe in the treatment of colon cancer $[1,2]$. In order to further improve upon the results of multiport laparoscopic colectomies (LACs), efforts have been made to further reduce the trauma caused by incisions. The rationale for further "scar-less" surgery is that decreasing the number and size of port accesses to the abdominal cavity might be an advantage not only from the cosmetic aspect but also in minimizing the risk of complications such as wound pain and infections as well as incision hernia and internal adhesion formation [7].
The excitement to develop new techniques has given rise to natural orifice transluminal endoscopic surgery (NOTES) [8-10]. This procedure in both animal [11] and human [12] models has shown some success but certainly has technical challenges: using transgastric, transvaginal, and transrectal access to the abdominal viscera and the need for expensive specialized equipment has hindered the widespread acceptance of this approach. Therefore use of the NOTES approach in performing routine colon resection is far from being practical at this time. Single-incision laparoscopic surgery (SILS) has advantages over NOTES in that existing laparoscopic instruments can be used and relatively minor adjustments from the current multiport laparoscopic technique are needed. The initial applications of SILS in gastrointestinal surgery were cholecystectomy [13], appendectomy [14] and recently, this technique has also been applied to colorectal surgery [15-18].

In comparison to multiport laparoscopic colectomy, the potential advantages of SILS are thought to be improved 


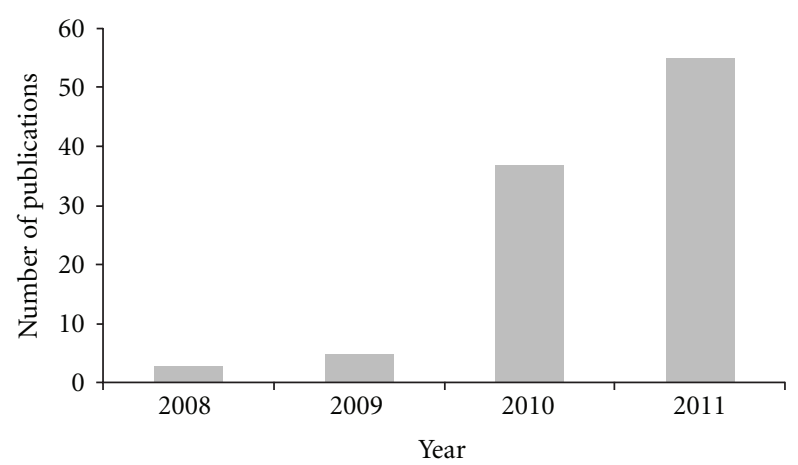

Figure 1: The number of publications regarding single-incision laparoscopic colectomy.

cosmesis as well as incisional and/or parietal pain and avoidance of port site-related complications [40]. Since 2008 when single-incision laparoscopic colectomy (SILC) was first introduced, the number of relevant publications has been increasing year by year as shown in Figure 1. However, because of still limited number of studies reporting SILC [41], its clinical significance remains to be elucidated. The aim of this study is to analyze current literature on SILC and access its potential benefits or efficacy as well as its feasibility and safety.

\section{Materials and Methods}

2.1. Literature Search Strategies. A systematic search of the scientific literature was carried out using the MEDLINE, EMBASE, the Cochrane Central Register of Controlled Trials ClinicalTrials.gov (Available at: http://clinicaltrials.gov/), National Research Register, The York (UK) Centre for Reviews, American College of Physicians (ACP) Journal Club, Australian Clinical Trials Registry, relevant online journals, and the Internet for the years 1983-August 2011 to obtain access to all relevant publications, especially randomized controlled trials, systematic reviews, and metaanalyses involving SILC. The search terms were "singleincision," "single port," "single access," "single site," "laparoscopic colectomy," "colectomy," and "laparoscopic colorectal surgery."

2.2. Inclusion and Exclusion Criteria. Articles were selected if the abstract contained data on patients who underwent SILC for colorectal diseases in the form of RCTs and other controlled or comparative studies. Conference abstracts were included if they contained relevant data. The reference lists of these articles were also reviewed to find additional candidate studies. Searches were conducted without language restriction. To avoid duplication of data, articles from the same unit or hospital were included only once if data was updated in a later publication. However, if surgical cases did not overlap among reports by even the same institute, these reports were all included. Reports with fewer than 10 cases of SILC and review articles were excluded from this study. Data extracted for this study were taken from the published reports; authors were not contacted to obtain additional information. All articles selected for full text review were distributed to 2 reviewers (T.M and S.L.), who independently decided on inclusion/exclusion and independently abstracted the study data. Any discrepancies in agreement were resolved by consensus. The flow chart of this selection process is summarized in Figure 2.

2.3. Result of the Literature Research. By using the above search strategy, a total of 249 potentially relevant citations were found. After the exception of 98 duplicated citations, we excluded 86 articles irrelevant of surgical specialty and 37 relevant articles with fewer than 10 cases by reviewing titles and abstracts. 28 publications were selected for review of full text, and 4 studies with no relevant data and 3 review articles were excluded from our paper. Twenty-one studies [19-39] with a total of 477 patients undergoing SILC met the criteria for analysis providing level 2-4 evidence (Table 1). There were one multi-institutional study and a total of 9 comparative studies including 6 case-matched ones between SILC and other minimally invasive procedures. There were no randomized controlled trials and meta-analyses in the selected literature.

\section{Results}

3.1. Indications and SILC Procedures. Demographic information and preoperative parameters are shown in Table 1. All studies except 4 performed SILC for colon cancer cases $[21,26,29,38]$. Among them, 18 studies also included benign colon disease (diverticulitis, Crohn's disease, ulcerative colitis, polyps, etc.) $[21,22,24-39]$. The most common surgical procedures performed in these series were right hemicolectomy $(n=277)$, followed by sigmoidectomy $(n=81)$. Anterior resections were performed in 5 of 22 studies $(n=37)$. Range of body mass index (BMI) was $21.9-30.0 \mathrm{~kg} / \mathrm{m}^{2}$ in each study.

3.2. Surgical Instruments and Skin Incision Length. All studies except one [30] used commercially available single port devices as summarized in Table 3. Chen et al. used a surgical glove attached with three trocars for the purpose of reestablishing the pneumoperitoneum after extraction of the specimen and anastomosis [30]. Ross et al., instead of a single access device, used multiple trocars placed through a single skin incision for some patients [32]. All studies, with exception of two $[29,34]$, utilized three ports/trocars $(5,5,5$, or $12 \mathrm{~mm})$ placed through the single access device. Sixteen studies reported on type of laparoscope used [2026, 29, 30, 32-38]. Most of investigators from the studies reported using $30^{\circ}$-angled scopes while two studies used $0^{\circ}$ laparoscopes [20, 21]. Types of instruments used are detailed in Table 3. The skin incision for the insertion of port systems initially measured 2 to $4 \mathrm{~cm}$, and average length of final scar was $2.7-4.5 \mathrm{~cm}$ in 7 studies [22, 23, 27, 31-33, 36] with relevant data. The final (at the end of operation) length of incision scar was longer than the initial one in all 11 studies with available data $[21-24,27,28,30,33-36]$. 


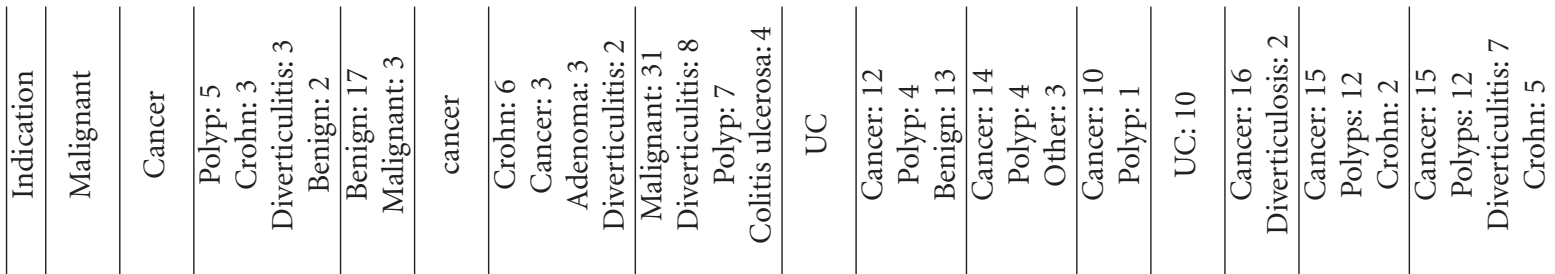

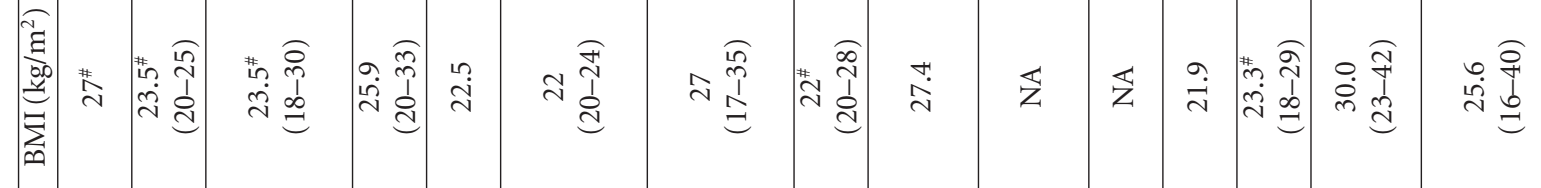

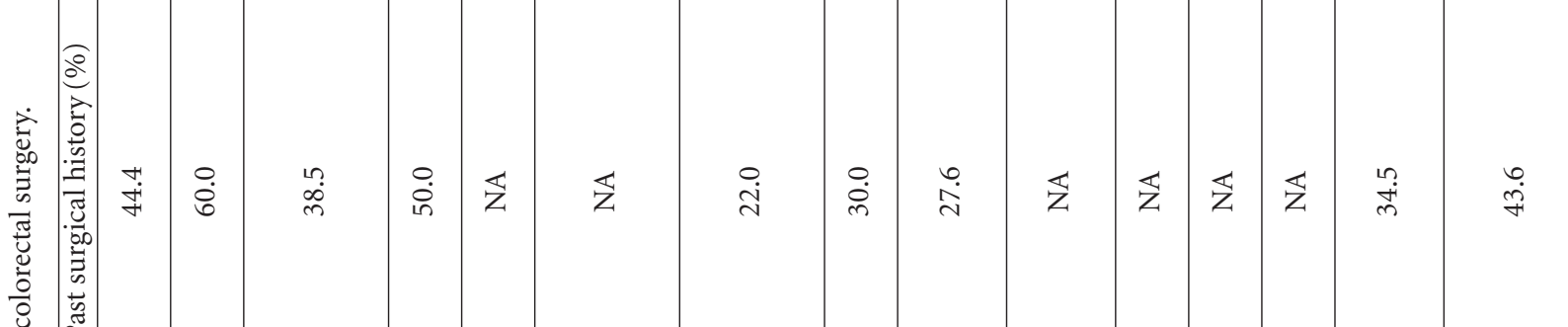

事

路

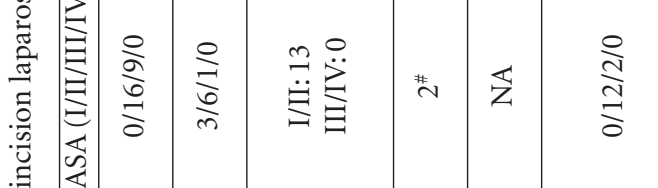

i

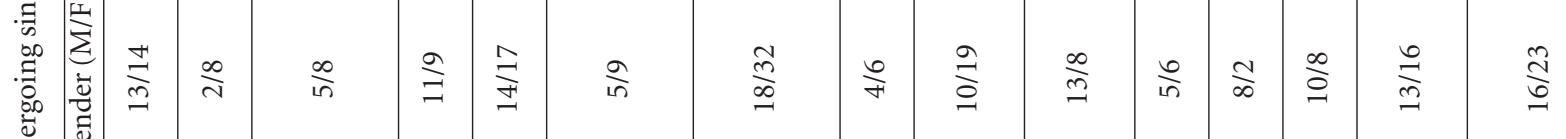

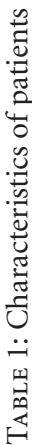

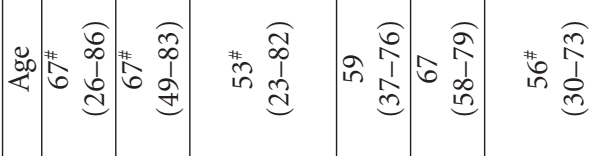

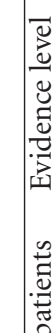

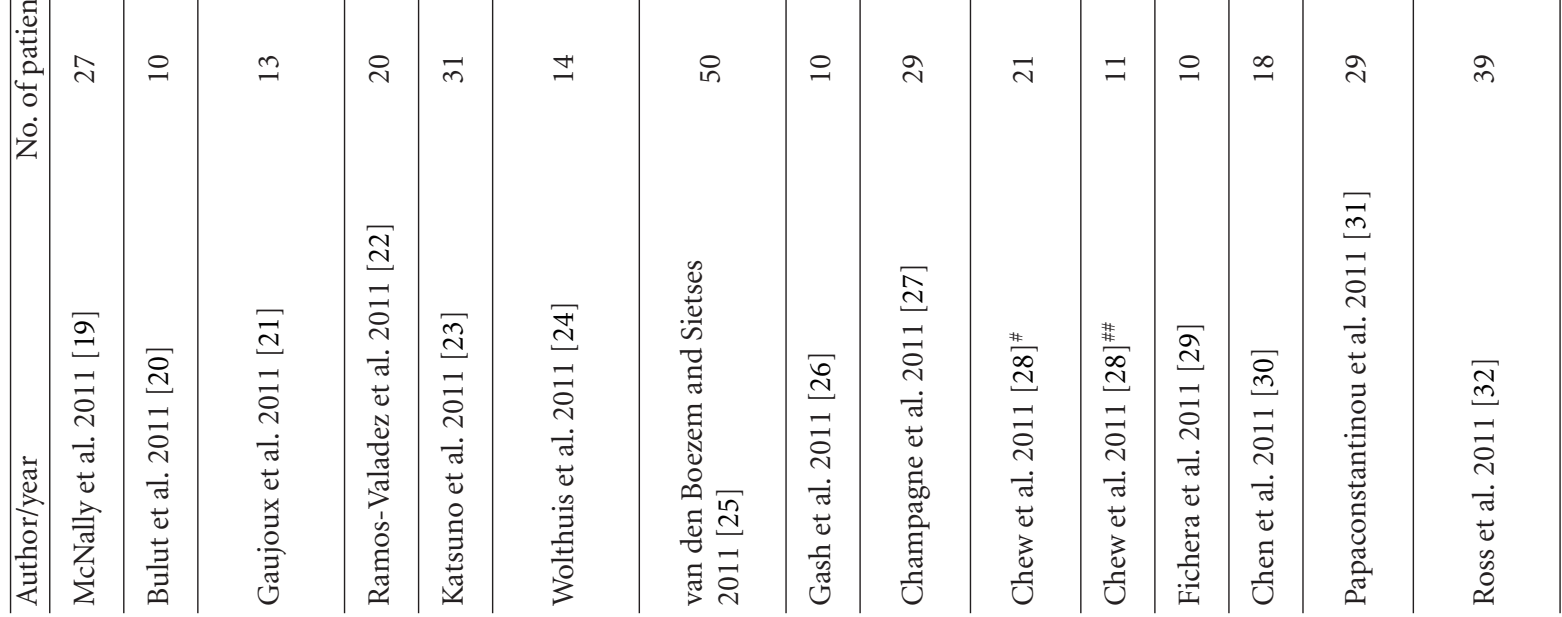




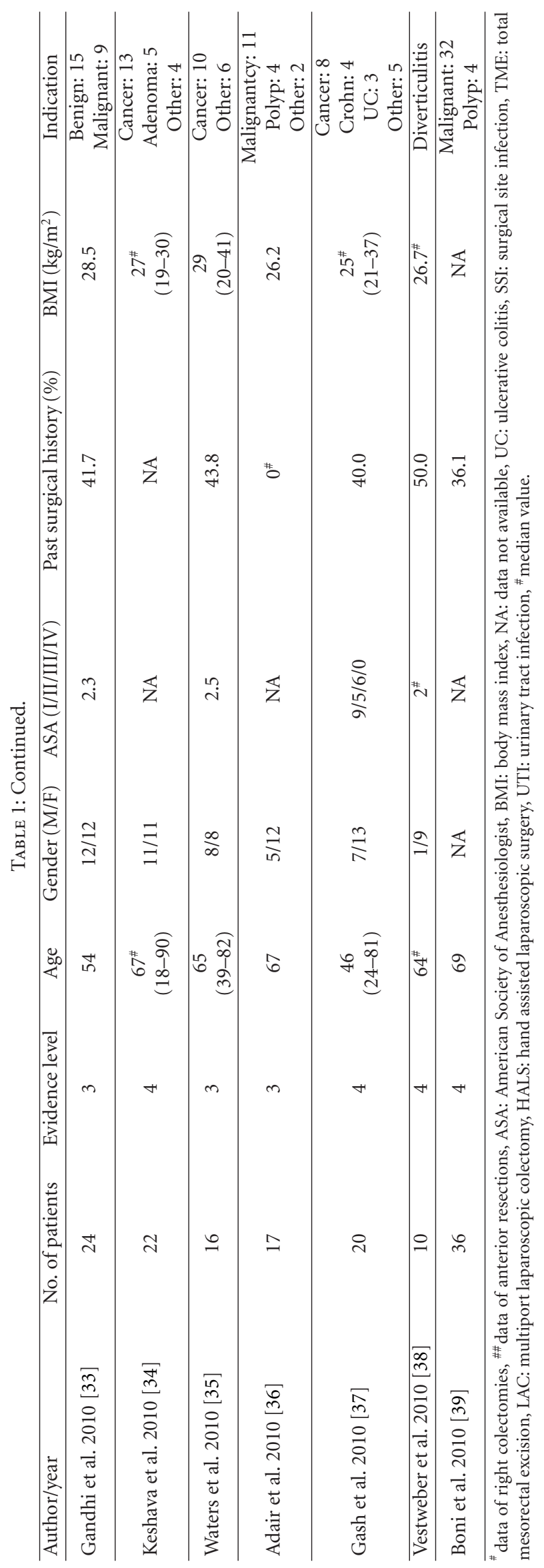




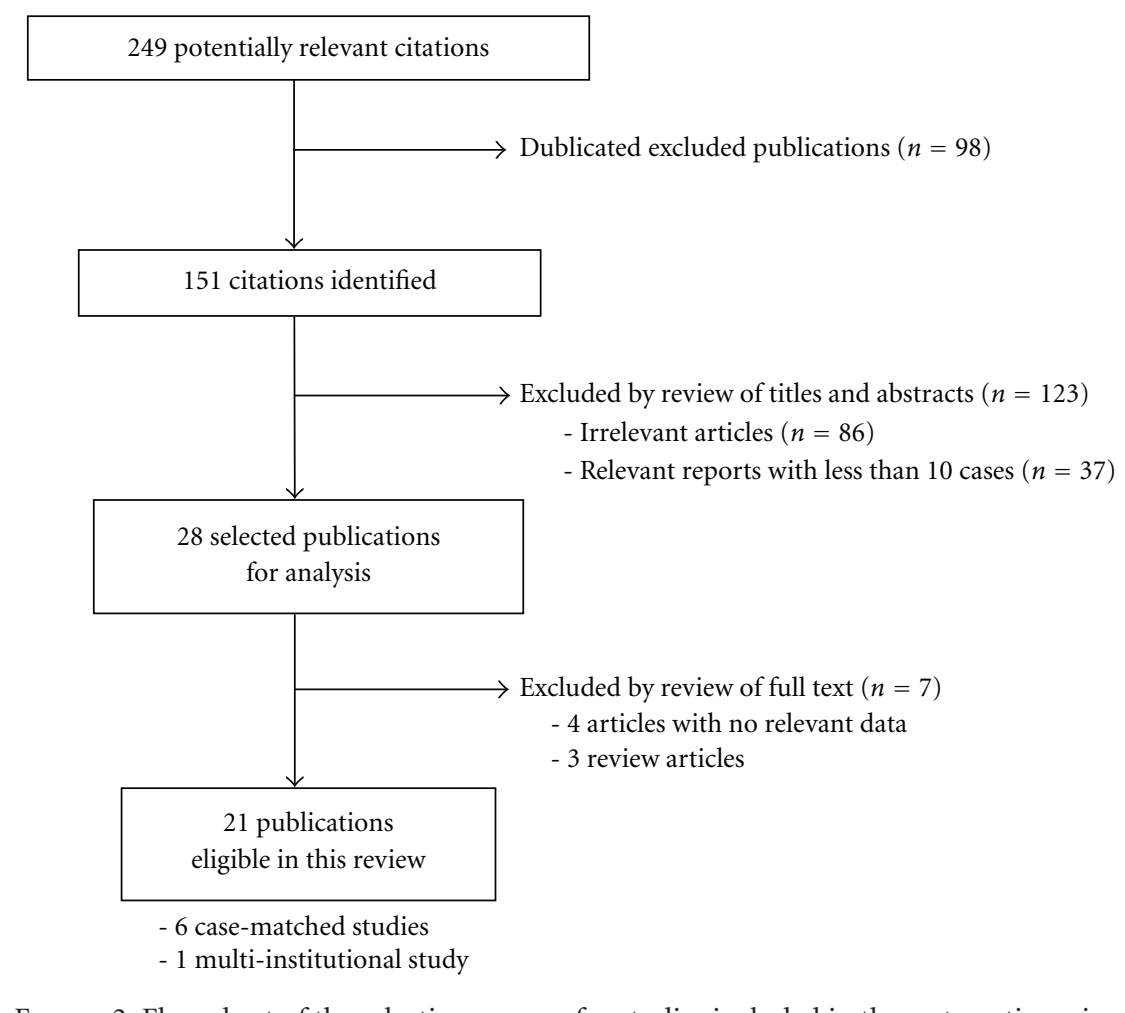

3.3. Intraoperative Parameters. The summary of various operative parameters is shown in Table 2. The range of operative times for SILC procedure was 75-229 minutes ( $n=21$ studies). The range of estimated blood loss was 0 $100 \mathrm{~mL}$ ( $n=14$ studies). Among all 477 cases eligible in the current paper, a total of 5 cases $(1.0 \%)$ were converted to open procedures, 3 cases $(0.6 \%)$ to hand-assisted laparoscopic surgeries (HALS), and 20 cases $(4.2 \%)$ to conventional (multiport) laparoscopic colectomies (LAC). Overall conversion rate was $5.9 \%(28 / 477)$. Reasons of conversion in these cases were the following: purpose for retraction or aid in colonic mobilization $(n=9)$, severe adhesion $(n=4)$, port trouble $(n=3)$, low-rectal lesions $(n=3)$, obesity $(n=3)$, bleeding $(n=1)$, fistula $(n=1)$, time constrains $(n=1)$, facilitating primary suture closure of colorectal anastomosis following a positive air insufflation test $(n=1)$, T4 tumor $(n=1)$, and unknown reason $(n=1)$. On the other hand, among 15 studies $(n=329)$ with available data, an additional port (adding only one port) was needed during the operation in a total of 16 cases $(4.9 \% ; 16 / 329)$. No major intraoperative complications were observed in these series.

3.4. Surgical Specimen. Five studies including right hemicolectomy, sigmoidectomy, and anterior resection showed that the range of specimen lengths was $15-43.5 \mathrm{~cm}$ (Table 4 ) $[20,24,27,28,35]$. All margins were free of cancer in these series. In 18 studies with available data, the range of number of removed lymph nodes for malignant cases and potential malignant diseases was 12-24.6 (Table 4) [19, 20, 22-25, 27, 28, 30-39].

\subsection{Postoperative Parameters}

3.5.1. Perioperative Mortality. Overall, 2 perioperative deaths $(0.4 \% ; 2 / 477)$ were observed. One death, reported by Adair et al., occurred on postoperative day 10, 8 days after discharge from the hospital, due to a pulmonary embolus [36]. Gandhi et al. reported another death, which was encountered in a patient following palliative SILC right hemicolectomy as a result of complications from metastatic disease [33].

3.5.2. Morbidity, Reoperation, and Length of Hospital Stay (LOS). Postoperative morbidities varied across studies (0-29.4\%). Overall 43 patients (11.7\%; 43/368) developed complications related to surgery. The most frequent complication was ileus $(n=10)$ and wound infection/hematoma/seroma $(n=10)$ followed by and anastomotic bleeding $(n=4)$ and arrhythmia $(n=3)$. Overall 6 out of 419 patients $(1.4 \%)$ required reoperation and the reasons in these cases were as follows: anastomotic leakage ( $n=2)$, anastomotic bleeding $(n=1)$, wound hematoma $(n=1)$, cecal ischemia with perforation $(n=1)$, and a negative relaparotomy to rule out anastomotic leakage $(n=$ 1). In all 21 studies, the range of length of hospital stay (LOS) also varied across reports: 2.7-9.2 days. Notably, 2 studies reported fewer than 3 days of LOS in their series $[33,37]$.

3.5.3. Postoperative Anesthesia. Katsuno et al. reported that analgesics were used $1.4 \pm 1.2$ times in addition to routinely using the epidural catheter $(0.2 \%$ ropivacaine hydrochloride hydrate $600 \mathrm{mg}$ plus morphine hydrochloride hydrate $8 \mathrm{mg}$ ) 


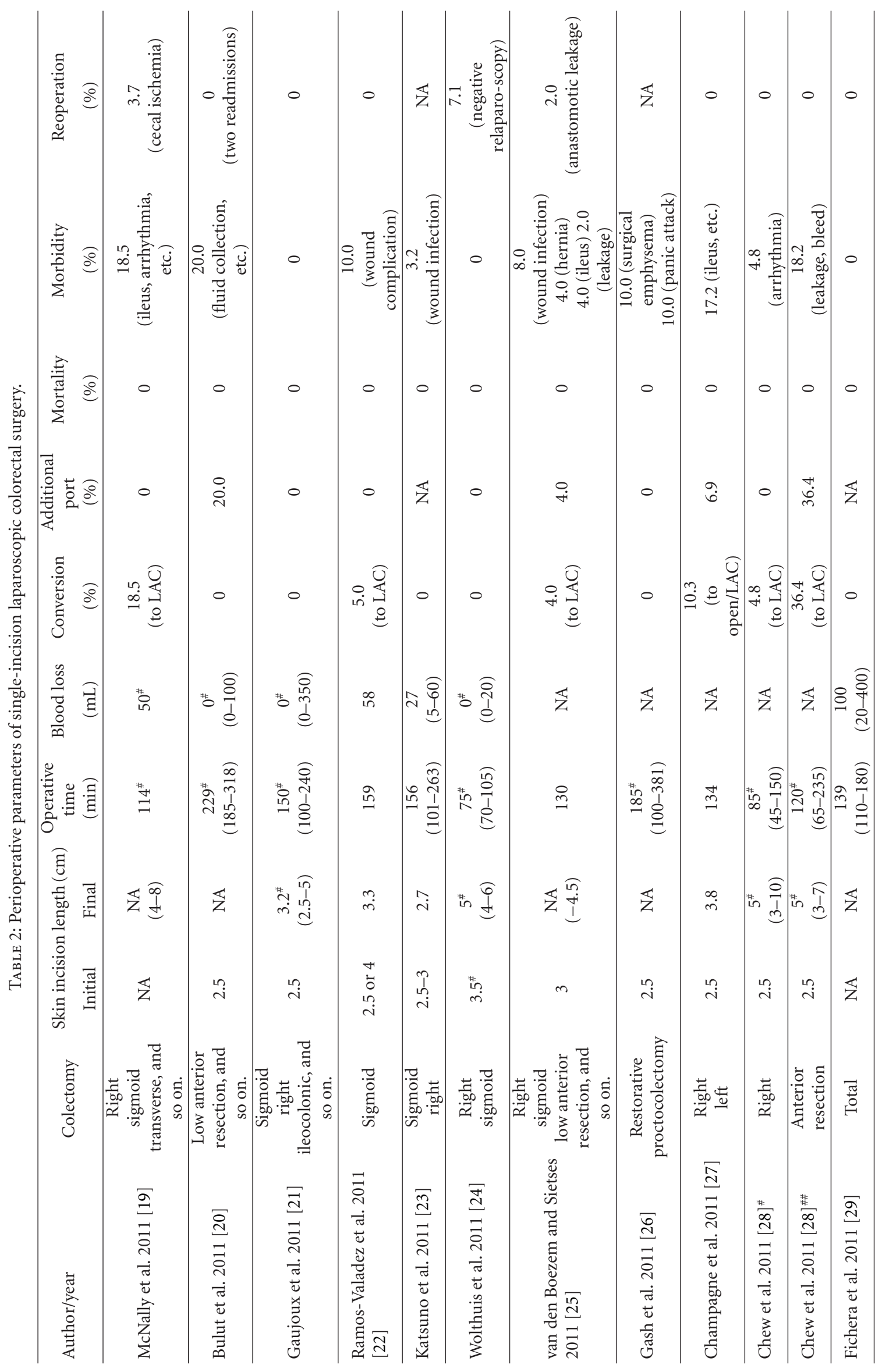




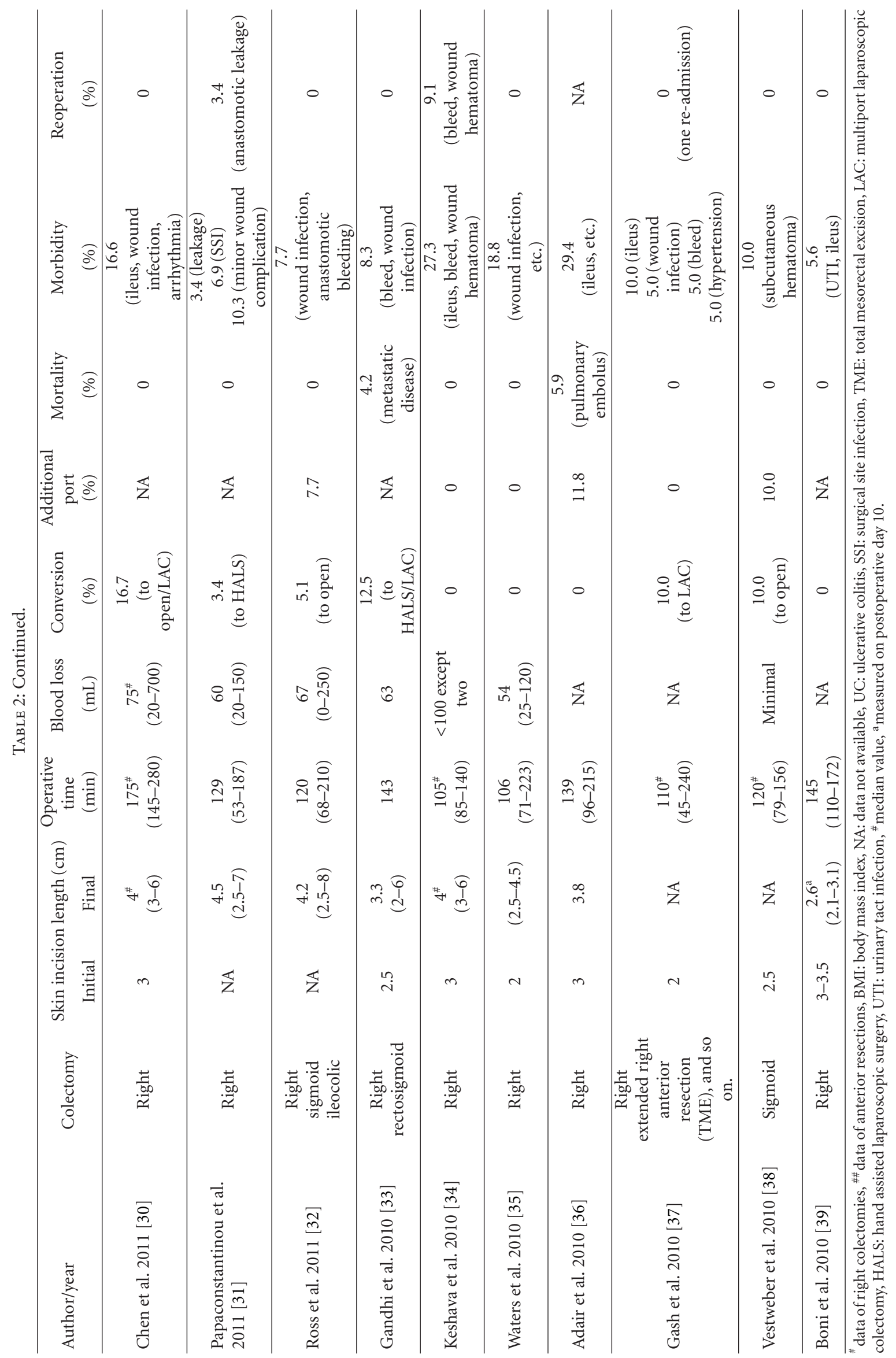




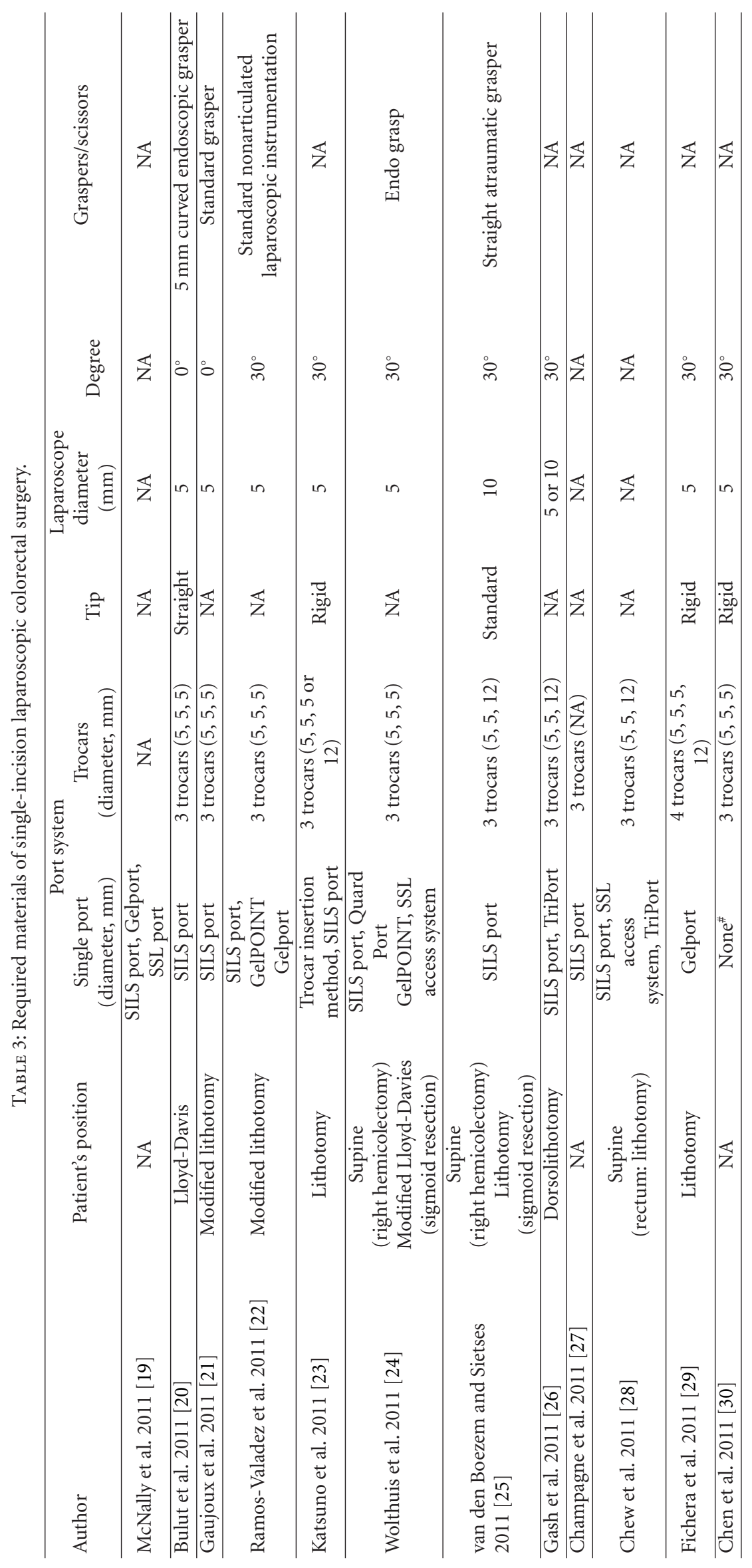




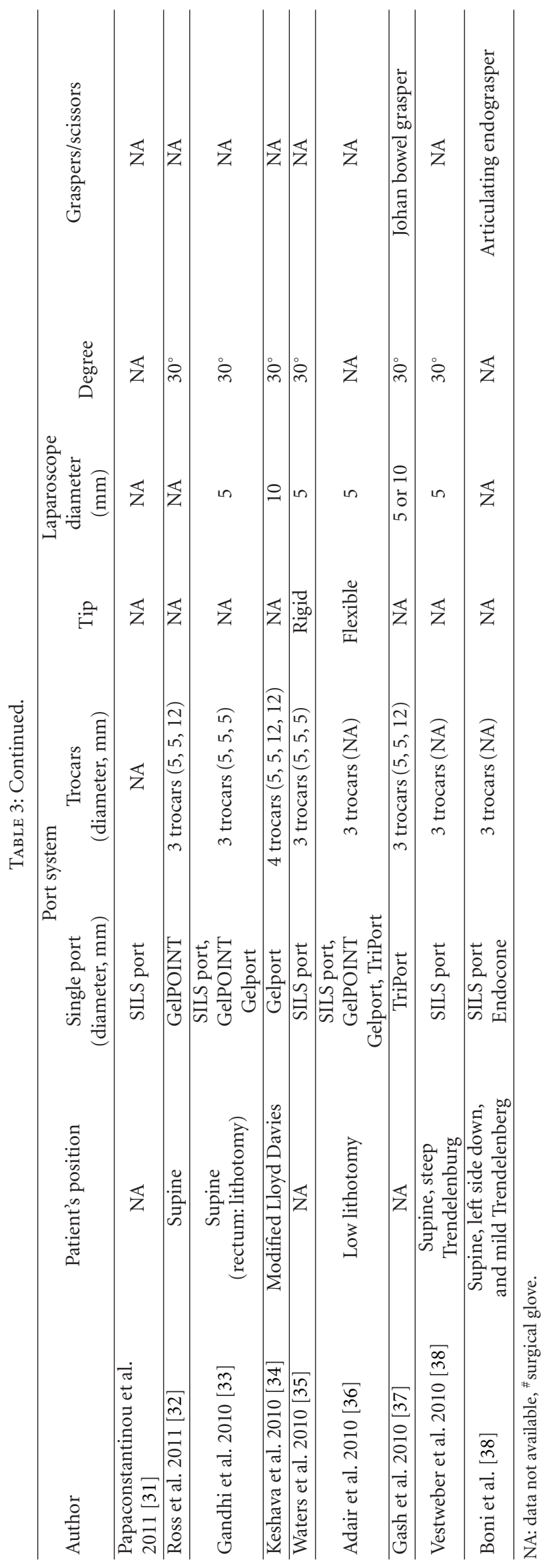




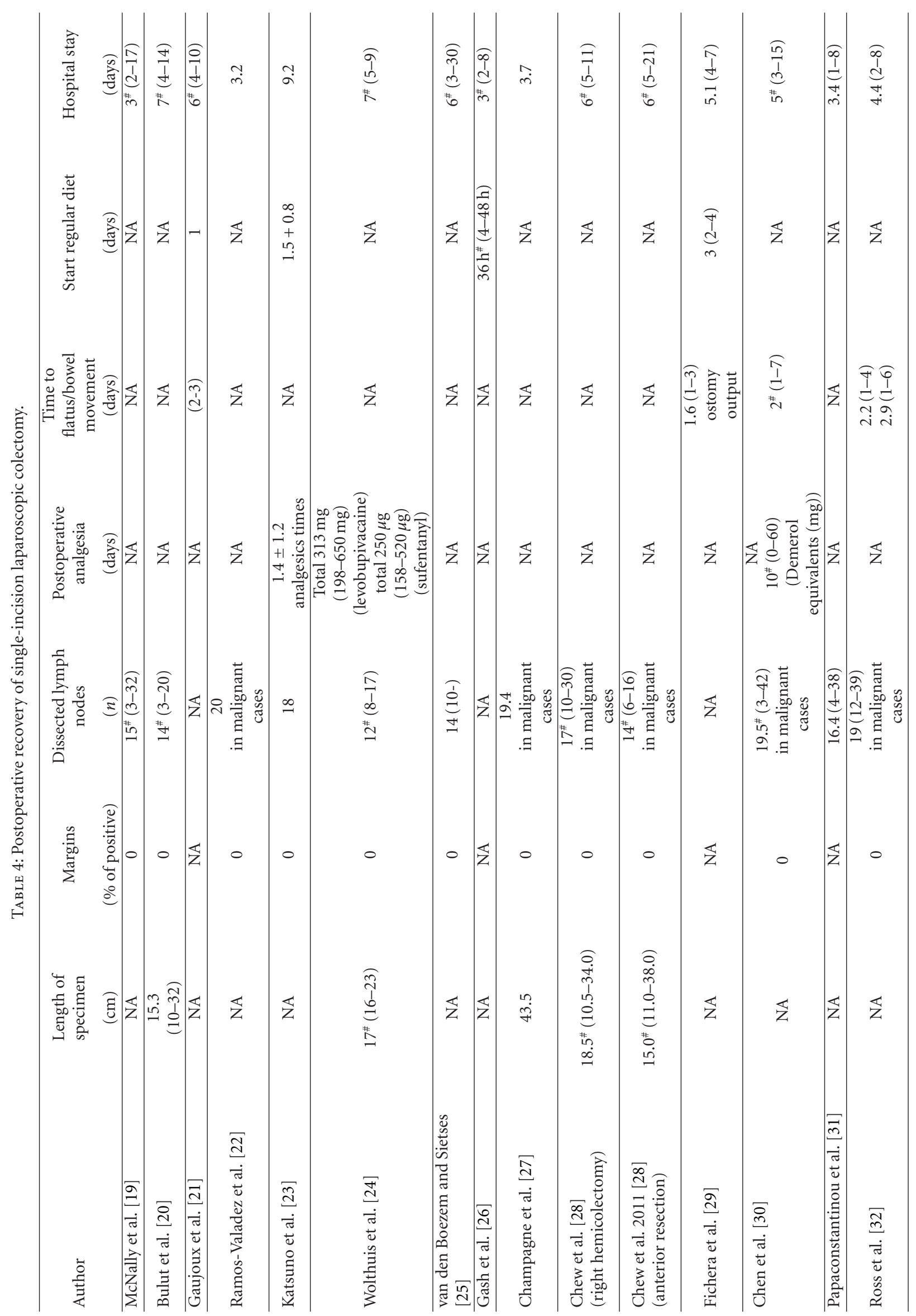




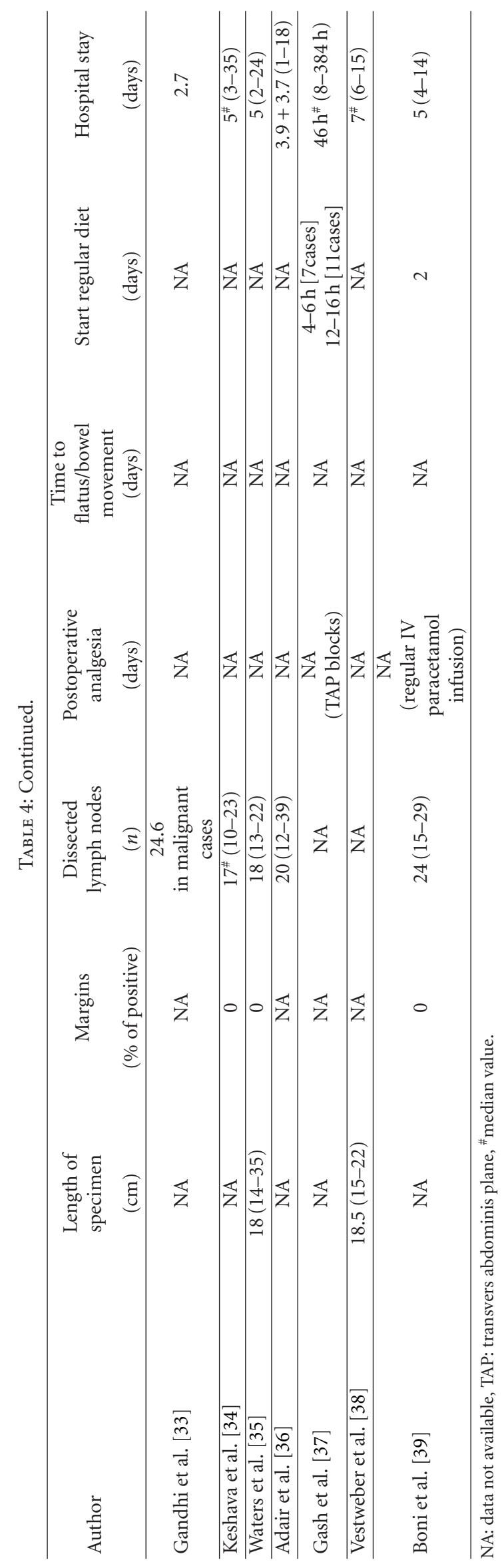


TABLE 5: Comparison of intraoperative parameters between single-incision laparoscopic colectomy and other minimally invasive surgeries.

\begin{tabular}{|c|c|c|c|c|c|c|}
\hline Author & Study type & $\begin{array}{l}\text { No. of patients } \\
\text { (groups) }\end{array}$ & $\begin{array}{c}\text { Incision length } \\
(\mathrm{cm})\end{array}$ & $\begin{array}{c}\text { Operative time } \\
(\min )\end{array}$ & $\begin{array}{c}\text { Blood loss } \\
(\mathrm{mL})\end{array}$ & Conversion (\%) \\
\hline McNally et al. [19] & No case matched & $\begin{array}{c}27 \text { versus } 46 \\
\text { (SILC versus LAC) }\end{array}$ & NA & $\begin{array}{c}114^{\#} \text { versus } 135^{\#} \\
(P=0.08)\end{array}$ & $\begin{array}{c}50^{\#} \text { versus } 50^{\#} \\
(P=0.21)\end{array}$ & $\begin{array}{c}0 \text { versus } 13.0 \\
(P=\mathrm{NA})\end{array}$ \\
\hline Ramos-Valadez et al. [22] & Case matched & $\begin{array}{c}20 \text { versus } 20 \\
\text { (SILC versus LAC) }\end{array}$ & $\begin{array}{c}3.3 \text { versus } 3.2 \\
(P<0.70)\end{array}$ & $\begin{array}{c}159 \text { versus } 162 \\
(P<0.80)\end{array}$ & $\begin{array}{l}58 \text { versus } 99 \\
(\boldsymbol{P}<\mathbf{0 . 0 0 7})\end{array}$ & 0 versus 0 \\
\hline Wolthuis et al. [24] & Case matched & $\begin{array}{c}14 \text { versus } 14 \\
\text { (SILC versus LAC) }\end{array}$ & $\begin{array}{c}5^{\#} \text { versus } 5^{\#} \\
(P=0.81)\end{array}$ & $\begin{array}{c}75^{\#} \text { versus } 83^{\#} \\
(P=0.31)\end{array}$ & $\begin{array}{c}0^{\#} \text { versus } 10^{\#} \\
(P=0.99)\end{array}$ & 0 versus 0 \\
\hline Champagne et al. [27] & Case matched & $\begin{array}{c}29 \text { versus } 29 \\
\text { (SILC versus LAC) }\end{array}$ & $\begin{array}{c}3.8 \text { versus } 4.5 \\
(P=0.098)\end{array}$ & $\begin{array}{c}134 \text { versus } 104 \\
(\boldsymbol{P}=\mathbf{0 . 0 0 0 2})\end{array}$ & NA & $\begin{array}{c}17.2 \text { versus } 6.9 \\
(P=0.11) \\
\end{array}$ \\
\hline Chen et al. [30] & Case matched & $\begin{array}{c}18 \text { versus } 21 \\
\text { (SILC versus LAC) }\end{array}$ & $\begin{array}{l}4^{\#} \text { versus } 4^{\#} \\
(P=0.52)\end{array}$ & $\begin{array}{c}175^{\#} \text { versus } 165^{\#} \\
(P=0.16)\end{array}$ & $\begin{array}{c}75^{\#} \text { versus } 50^{\#} \\
(P=0.67) \\
\end{array}$ & $\begin{array}{c}16.7 \text { versus } 0 \\
(P=0.052) \\
\end{array}$ \\
\hline $\begin{array}{l}\text { Papaconstantinou et al. } \\
\text { [31] }\end{array}$ & Case matched & $\begin{array}{c}29 \text { versus } 29 \text { versus } \\
29 \\
\text { (SILC versus LAC } \\
\text { versus HALS) }\end{array}$ & $\begin{array}{c}4.5 \text { versus } 5.1 \\
\text { versus } 7.1 \\
(\boldsymbol{P}<\mathbf{0 . 0 5})\end{array}$ & $\begin{array}{l}129 \text { versus } 128 \\
\text { versus } 116 \\
(P=0.27)\end{array}$ & $\begin{array}{c}60 \text { versus } 90 \\
\text { versus } 71 \\
(P=0.19)\end{array}$ & $\begin{array}{c}3.4 \text { versus } 13.8 \\
\text { versus } 13.8 \\
(P=0.20)\end{array}$ \\
\hline Gandhi et al. [33] & Case matched & $\begin{array}{c}24 \text { versus } 24 \\
\text { (SILC versus HALS) }\end{array}$ & $\begin{array}{l}3.3 \text { versus } 6.6 \\
(\boldsymbol{P}<\mathbf{0 . 0 0 0 0 1 )} \\
\end{array}$ & $\begin{array}{c}143 \text { versus } 113 \\
(\boldsymbol{P}=\mathbf{0 . 0 0 0 4})\end{array}$ & $\begin{array}{c}63 \text { versus } 91 \\
(P=0.06)\end{array}$ & $\begin{array}{c}12.5 \text { versus } 0 \\
(P=0.083)\end{array}$ \\
\hline Waters et al. [35] & No case matched & $\begin{array}{c}16 \text { versus } 27 \\
\text { (SILC versus LAC) }\end{array}$ & NA & $\begin{array}{c}106 \text { versus } 100 \\
(P=0.64)\end{array}$ & $\begin{array}{c}54 \text { versus } 90 \\
(P=0.07)\end{array}$ & 0 versus 0 \\
\hline Adair et al. [36] & Case matched & $\begin{array}{c}17 \text { versus } 17 \\
\text { (SILC versus LAC) }\end{array}$ & $\begin{array}{c}3.8 \text { versus } 5.1 \\
\text { (extraction port } \\
\text { size) }\end{array}$ & $\begin{array}{l}139 \text { versus } 134 \\
(P=0.61)\end{array}$ & NA & NA \\
\hline
\end{tabular}

NA: data not available, SILC: single-incision laparoscopic colectomy, LAC: multiport laparoscopic colectomy, HALS: hand-assisted laparoscopic surgery (colectomy), ${ }^{\#}$ median value.

for the first 2 to 3 days as postoperative anesthesia and no patients required analgesics after the fourth postoperative day [23]. Wolthuis et al. reported that total consumption of levobupivacaine ( 313 versus $355 \mathrm{mg}$ ) and sufentanyl (250 versus $284 \mu \mathrm{g}$ ) provided by epidural infusion with a patientscontrolled bolus capability was similar between SILC and LAC groups $(P=0.94)$ [24]. Chen et al. also found no difference in the postoperative usage of intravenous narcotics (Demerol) between SILC and LAC groups (10 versus $10 \mathrm{mg}$, $P=0.82$ ) [30].

\subsubsection{Postoperative Recovery of Gastrointestinal Function.} Several reports $[21,23,26,29,30,37,39]$ provided data regarding postoperative recovery of gastrointestinal function; Gash et al. [37], in their analysis of 20 SILC procedures, reported that a normal diet was tolerated in 46 hours by 7 patients and in 12-16 hours (overnight) by 11 patients. In 39 SILC cases [32] from multi-institutional studies reviewed, average time to flatus and bowel movement were Days 2.2 and 2.9, respectively, which is supported by 2 other reports (p.o. Day 2-3 of first flatus) [21, 30, $42,43]$. Chen et al., in their case-control study comparing SILS right hemicolectomy to traditional laparoscopic right hemicolectomy, also reported that there was no difference in time until flatus passage (median 2 versus 2 days) [30]. Concerning oral intake after surgeries, Boni et al. [39] reported p.o. Day 2 for first oral fluid intake. In early experience with 31 SILC cases for colon cancer, Katsuno et al. reported that the time to adequate oral intake was $1.5 \pm 0.8$ days [23].
3.6. Comparative Studies: SILC versus Other Minimally Invasive Surgeries. A total of 9 comparative studies [19, 22, 24, $27,30,31,33,35,36]$ including 6 case-matched studies $[22,24,27,31,33,36]$ between SILC and other minimally invasive procedures are summarized in Tables 5 and 6 . Ramos-Valadez et al., in their case-matched series (SILC versus LAC group), reported that mean estimated blood loss was significantly lower for the SILC group $(n=20)$ compared to the LAC group $(n=20)(58$ versus $99 \mathrm{~mL}, P<$ 0.007 ) [22]. Champagne et al., in their case-controlled study comparing SILC $(n=29)$ versus laparoscopic-assisted $(n=$ 29) segmental colectomy, reported that SILC is feasible and safe but takes longer time in surgery (134 versus $104 \mathrm{~min} P=$ 0.0002 ) [27]. There were no short-term outcome benefits associated with SILC. Chen et al. also did not find any significant benefits associated with right hemicolectomy by SILS approach compared to the same procedure by the multiport laparoscopic approach [30]. McNally et al., comparing 27 SILC cases with 46 LAC cases, reported relatively shorter LOS in SILC versus LAC cases (3 versus 5 days) but with no statistical significance $(P=0.07)$. Gandhi et al., comparing 24 case-matched patients undergoing right hemicolectomy or anterior rectosigmoidectomy between SILC and handassisted laparoscopic colectomy (HALC), reported that the average operative time was longer in SILC as compared to HALC (143 versus 113 min $P=0.0004$ ) while there was no difference in conversion rate or perioperative complications [33]. Importantly, average LOS was significantly shorter in the SILC group compared with the HALC group (2.7 versus 3.3 days $P<0.02$ ), which was also supported by another 


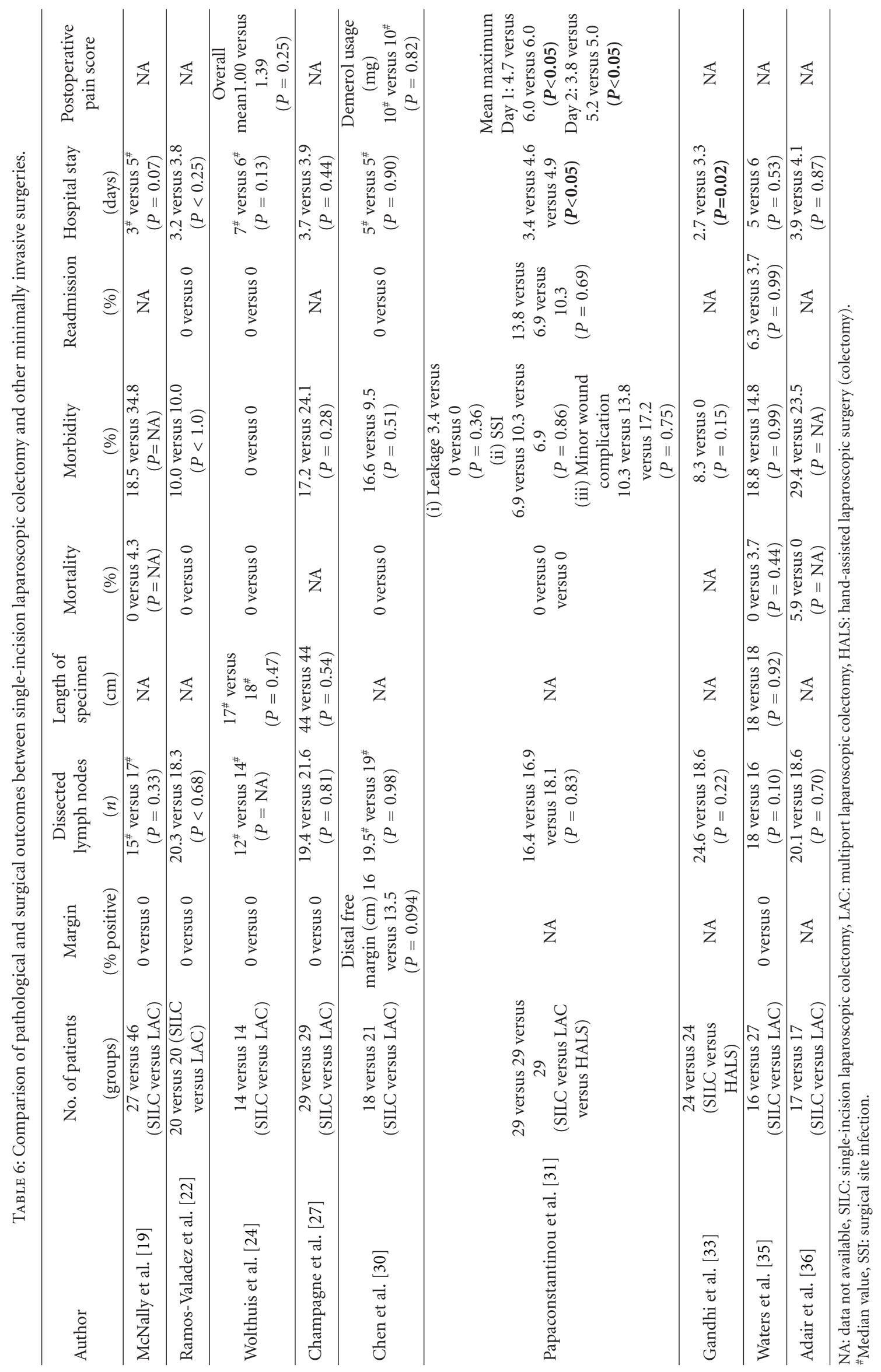


case-matched study performing right colectomies where Papaconstantinou et al. [31] reported that LOS was significantly shorter in the SILC group $(n=29)$ compared to LAC $(n=29)$ and HALC $(n=29)$ groups (3.4 versus 4.6 versus 4.9 days, $P<0.05)$. In addition, maximum pain scores on p.o. Days 1 and 2 were significantly lower in the SILC group compared to LAC and HALC groups $(P<0.05)$. On the other hand, in comparison between 16 single-port and 27 conventional laparoscopic right hemicolectomies of similar clinical background, Waters et al. concluded that no significant difference of short-term outcomes was observed between the 2 groups [35]. Adair et al., in their case-matched analysis of 17 single-port and multiport laparoscopic right colectomy cases, also found similar short-term outcomes between the 2 groups [36]. Wolthuis et al., in their casematched study between SILC $(n=14)$ and LAC $(n=14)$ examining postoperative inflammatory response, reported that C-reactive protein (CRP) levels changed similarly in both groups $(P=0.34)$.

\section{Discussion}

Potential advantages of SILC over other minimally invasive surgeries include a single small skin incision. The length of the skin incision is partly determined by the size of the resected specimen. Extraction difficulties may be encountered with large colon tumors or with obese patients with thick mesentery, omentum, or deep abdominal wall and colon filled with stool. In fact, our paper revealed that the final (at the end of operation) length of incision scar was longer than the initial one in all relevant reports, suggesting that cosmetic analysis on SILC should be based on final, not initial, scar length and objectively based on cosmesis scale or body image scale which has not yet been examined in any literature. In theory, a single midline fascial incision may minimizes trauma to the abdominal muscles, epigastric articles, and parietal nerves made by multiple trocars in LAC cases. This potentially leads to less postoperative pain and long-term additional port site complications; one out of two case-matched studies demonstrated significantly less postoperative pain score in SILC group as compared to LAC and HALS groups although another study failed to show less postoperative use of anesthesia in SILC group.

When introducing any new technology, one significant limitation is often the cost of the procedure. Generally, the initial increases in operative costs associated with laparoscopic techniques are mitigated by reduction in morbidity and duration of hospital stay as a result of the minimally invasive surgery. In fact, several studies which examined both short-term and long-term costs associated with laparoscopic colectomy showed an initial increase in the cost associated with laparoscopic colectomy but a longterm, overall saving. The potential challenge with SILC is that it will require purchase of proprietary instrumentation and additional equipments in some cases which increase overall operative cost. Although potential benefits including fewer conversions, a shorter postoperative recovery or LOS, and less morbidity would make SILC more cost effective, demonstration of any economic benefit over LAC can be difficult. Waters et al. [35] reported that the port itself was purchased at a cost of 550-650 USD compared with average cost of 80 USD of the ports used in the standard LAC cases. The marginal increase in direct operative cost was 310410 USD per case. With similar operative time and LOS, it can be inferred that the total increase in cost is only that of the port device itself.

Concerning surgical instruments and techniques, SILS has several disadvantages compared with multiport laparoscopic surgery. Standard laparoscopic surgeries are performed through multiports allowing variation of scope placement and angling when met with obstructions. In SILS, no additional ports exist for placement of the scope and maneuvering is greatly restricted by nearby instruments. Therefore SILS requires an experienced surgeon to overcome the difficulties of triangulation, pneumoperitoneum leaks, and instrument crowding. In fact, according to our paper, as many as 9 cases needed to be converted to either open or multiports laparoscopic procedure to get better retraction or aid in colonic mobilization. Some investigators recommend utilizing articulating instruments or since obesity was found to be a common reason for conversion, variable length tools including a bariatric-length bowel grasper or an extralong laparoscope to minimize external clashing are also recommended $[19,30]$. One of the most challenging factors for SILC in attaining widespread use is the additional learning curve required for this technique. The SILC is essentially a one-operating surgeon technique which has a potentially detrimental impact upon resident education, affecting the training of future surgeons as well. Because most surgeons are still performing open colectomy (the prevalence of even standard LAC procedure is still under $25 \%$ in the US $[44,45])$ or are on their own learning curve for laparoscopy, it requires further analysis to determine the impact that introducing a more technically demanding procedure has on training these surgeons.

\section{Conclusions}

SILC is a challenging procedure but seems to be feasible and safe when performed by surgeons highly skilled in laparoscopy. SILC may have potential benefits over other types of minimally invasive surgeries (LAC or HALC), however this has not yet been objectively shown. In the future, randomized controlled trials with a large number of cases are necessary to determine the role of SILC in cost benefit, cosmetic, and oncologic outcomes.

\section{Conflict of Interests}

The authors declare that they have no conflict of interests.

\section{References}

[1] H. J. Bonjer, W. C. Hop, H. Nelson et al., "Laparoscopically assisted vs open colectomy for colon cancer: a meta-analysis," Archives of Surgery, vol. 142, no. 3, pp. 298-303, 2007. 
[2] H. Nelson, D. J. Sargent, H. S. Wieand et al., "A comparison of laparoscopically assisted and open colectomy for colon cancer," The New England Journal of Medicine, vol. 350, no. 20, pp. 2050-2114, 2004.

[3] C. Laurent, F. Leblanc, F. Bretagnol, M. Capdepont, and E. Rullier, "Long-term wound advantages of the laparoscopic approach in rectal cancer," British Journal of Surgery, vol. 95, no. 7, pp. 903-908, 2008.

[4] S. D. Wexner, P. Reissman, J. Pfeifer, M. Bernstein, and N. Geron, "Laparoscopic colorectal surgery: analysis of 140 cases," Surgical Endoscopy, vol. 10, no. 2, pp. 133-136, 1996.

[5] K. Okabayashi, H. Hasegawa, M. Watanabe et al., "Indications for laparoscopic surgery for Crohn's disease using the Vienna Classification," Colorectal Disease, vol. 9, no. 9, pp. 825-829, 2007.

[6] U. Hildebrandt, K. Kessler, T. Plusczyk, G. Pistorius, B. Vollmar, and M. D. Menger, "Comparison of surgical stress between laparoscopic and open colonic resections," Surgical Endoscopy and Other Interventional Techniques, vol. 17, no. 2, pp. 242-246, 2003.

[7] C. G. Schmedt, B. J. Leibl, P. Däubler, and R. Bittner, "Access-related complications-an analysis of 6023 consecutive laparoscopic hernia repairs," Minimally Invasive Therapy and Allied Technologies, vol. 10, no. 1, pp. 23-29, 2001.

[8] K. Nakajima, T. Nishida, T. Takahashi et al., "Partial gastrectomy using natural orifice translumenal endoscopic surgery (NOTES) for gastric submucosal tumors: early experience in humans," Surgical Endoscopy and Other Interventional Techniques, vol. 23, no. 12, pp. 2650-2655, 2009.

[9] C. Rolanda, E. Lima, J. M. Pêgo et al., "Third-generation cholecystectomy by natural orifices: transgastric and transvesical combined approach," Gastrointestinal Endoscopy, vol. 65, no. 1, pp. 111-117, 2007.

[10] A. A. Gumbs, D. Fowler, L. Milone et al., "Transvaginal natural orifice translumenal endoscopic surgery cholecystectomy: early evolution of the technique," Annals of Surgery, vol. 249, no. 6, pp. 908-912, 2009.

[11] S. Perretta, B. Dallemagne, D. Coumaros, and J. Marescaux, "Natural orifice transluminal endoscopic surgery: transgastric cholecystectomy in a survival porcine model," Surgical Endoscopy and Other Interventional Techniques, vol. 22, no. 4, pp. 1126-1130, 2008.

[12] J. Marescaux, B. Dallemagne, S. Perretta, A. Wattiez, D. Mutter, and D. Coumaros, "Surgery without scars: report of transluminal cholecystectomy in a human being," Archives of Surgery, vol. 142, no. 9, pp. 823-826, 2007.

[13] P. P. Rao, S. M. Bhagwat, A. Rane, and P. P. Rao, “The feasibility of single port laparoscopic cholecystectomy: a pilot study of 20 cases," HPB, vol. 10, no. 5, pp. 336-340, 2008.

[14] G. Rispoli, M. F. Armellino, and C. Esposito, "One-trocar appendectomy: sense and nonsense," Surgical Endoscopy and Other Interventional Techniques, vol. 16, no. 5, pp. 833-835, 2002.

[15] P. Bucher, F. Pugin, and P. Morel, "Single port access laparoscopic right hemicolectomy," International Journal of Colorectal Disease, vol. 23, no. 10, pp. 1013-1016, 2008.

[16] F. H. Remzi, H. T. Kirat, and D. P. Geisler, "Laparoscopic single-port colectomy for sigmoid cancer," Techniques in Coloproctology, vol. 14, no. 3, pp. 253-255, 2010.

[17] A. M. Merchant and E. Lin, "Single-incision laparoscopic right hemicolectomy for a colon mass," Diseases of the Colon and Rectum, vol. 52, no. 5, pp. 1021-1024, 2009.
[18] F. H. Remzi, H. T. Kirat, J. H. Kaouk, and D. P. Geisler, "Singleport laparoscopy in colorectal surgery," Colorectal Disease, vol. 10, no. 8, pp. 823-826, 2008.

[19] M. E. McNally, B. Todd Moore, and K. M. Brown, "Singleincision laparoscopic colectomy for malignant disease," Surgical Endoscopy, vol. 25, no. 11, pp. 3559-3565, 2011.

[20] O. Bulut, C. B. Nielsen, and N. Jespersen, "Single-port access laparoscopic surgery for rectal cancer: initial experience with 10 cases," Diseases of the Colon \& Rectum, vol. 54, no. 7, pp. 803-809, 2011.

[21] S. Gaujoux, F. Bretagnol, M. Ferron, and Y. Panis, "Singleincision laparoscopic colonic surgery," Colorectal Disease, vol. 13, no. 9, pp. 1066-1071, 2011.

[22] D. I. Ramos-Valadez, M. Ragupathi, J. Nieto et al., "Singleincision versus conventional laparoscopic sigmoid colectomy: a case-matched series," Surgical Endoscopy, vol. 26, no. 1, pp. 96-102, 2011.

[23] G. Katsuno, M. Fukunaga, K. Nagakari, S. Yoshikawa, M. Ouchi, and Y. Hirasaki, "Single-incision laparoscopic colectomy for colon cancer: early experience with 31 cases," Diseases of the colon and rectum, vol. 54, no. 6, pp. 705-710, 2011.

[24] A. M. Wolthuis, F. Penninckx, S. Fieuws, and A. D'Hoore, "Outcomes for case-matched single port colectomy are comparable with conventional laparoscopic colectomy," Colorectal Disease, vol. 14, no. 5, pp. 634-641, 2012.

[25] P. B. van den Boezem and C. Sietses, "Single-incision laparoscopic colorectal surgery, experience with 50 consecutive cases," Journal of Gastrointestinal Surgery, pp. 1-6, 2011.

[26] K. J. Gash, A. C. Goede, B. Kaldowski, B. Vestweber, and A. R. Dixon, "Single incision laparoscopic (SILS) restorative proctocolectomy with ileal pouch-anal anastomosis," Surgical Endoscopy, vol. 54, no. 2, pp. 183-186, 2011.

[27] B. J. Champagne, E. C. Lee, F. Leblanc, S. L. Stein, and C. P. Delaney, "Single-incision vs straight laparoscopic segmental colectomy: a case-controlled study," Diseases of the Colon and Rectum, vol. 54, no. 2, pp. 183-186, 2011.

[28] M. H. Chew, M. T. C. Wong, B. Y. K. Lim, K. H. Ng, and K. W. Eu, "Evaluation of current devices in single-incision laparoscopic colorectal surgery: a preliminary experience in 32 consecutive cases," World Journal of Surgery, vol. 35, no. 4, pp. 873-880, 2011.

[29] A. Fichera, M. Zoccali, and R. Gullo, "Single Incision ("Scarless") laparoscopic total abdominal colectomy with end Ileostomy for ulcerative colitis," Journal of Gastrointestinal Surgery, vol. 15, no. 7, pp. 1247-1251, 2011.

[30] W. T. L. Chen, S. C. Chang, H. C. Chiang et al., "Singleincision laparoscopic versus conventional laparoscopic right hemicolectomy: a comparison of short-term surgical results," Surgical Endoscopy, vol. 25, no. 6, pp. 1887-1892, 2011.

[31] H. T. Papaconstantinou, N. Sharp, and J. S. Thomas, "Single-incision laparoscopic right colectomy: a case-matched comparison with standard laparoscopic and hand-assisted laparoscopic techniques," Journal of the American College of Surgeons, vol. 213, no. 1, pp. 72-80, 2011.

[32] H. Ross, S. Steele, M. Whiteford et al., "Early multi-institution experience with single-incision laparoscopic colectomy," Diseases of the Colon and Rectum, vol. 54, no. 2, pp. 187-192, 2011.

[33] D. P. Gandhi, M. Ragupathi, C. B. Patel, D. I. RamosValadez, T. B. Pickron, and E. M. Haas, "Single-incision versus hand-assisted laparoscopic colectomy: a case-matched series," Journal of Gastrointestinal Surgery, vol. 14, no. 12, pp. 18751880, 2010. 
[34] A. Keshava, C. J. Young, and S. MacKenzie, "Single-incision laparoscopic right hemicolectomy," British Journal of Surgery, vol. 97, no. 12, pp. 1881-1883, 2010.

[35] J. A. Waters, M. J. Guzman, A. D. Fajardo et al., "Singleport laparoscopic right hemicolectomy: a safe alternative to conventional laparoscopy," Diseases of the Colon and Rectum, vol. 53, no. 11, pp. 1467-1472, 2010.

[36] J. Adair, M. A. Gromski, R. B. Lim, and D. Nagle, "Singleincision laparoscopic right colectomy: experience with 17 consecutive cases and comparison with multiport laparoscopic right colectomy," Diseases of the Colon and Rectum, vol. 53, no. 11, pp. 1549-1554, 2010.

[37] K. J. Gash, A. C. Goede, W. Chambers, G. L. Greenslade, and A. R. Dixon, "Laparoendoscopic single-site surgery is feasible in complex colorectal resections and could enable day case colectomy," Surgical Endoscopy and Other Interventional Techniques, vol. 25, no. 3, pp. 835-840, 2011.

[38] B. Vestweber, A. Alfes, C. Paul, F. Haaf, and K. H. Vestweber, "Single-incision laparoscopic surgery: a promising approach to sigmoidectomy for diverticular disease," Surgical Endoscopy and Other Interventional Techniques, vol. 24, no. 12, pp. 3225$3228,2010$.

[39] L. Boni, G. Dionigi, E. Cassinotti et al., "Single incision laparoscopic right colectomy," Surgical Endoscopy and Other Interventional Techniques, vol. 24, no. 12, pp. 3233-3236, 2010.

[40] N. A. Rieger and F. F. Lam, "Single-incision laparoscopically assisted colectomy using standard laparoscopic instrumentation," Surgical Endoscopy and Other Interventional Techniques, vol. 24, no. 4, pp. 888-890, 2010.

[41] T. Makino, J. Milsom, and S. Lee, "Feasibility and safety of single incision laparoscopic colectomy: a systematic review," Annals of Surgery, vol. 255, no. 4, pp. 667-676, 2012.

[42] D. Pietrasanta, N. Romano, V. Prosperi, L. Lorenzetti, G. Basili, and O. Goletti, "Single-incision laparoscopic right colectomy for cancer: a single-centre preliminary experience," Updates in Surgery, vol. 62, no. 2, pp. 111-115, 2010.

[43] D. P. Geisler, H. T. Kirat, and F. H. Remzi, "Single-port laparoscopic total proctocolectomy with ileal pouch-anal anastomosis: initial operative experience," Surgical Endoscopy and Other Interventional Techniques, vol. 25, no. 7, pp. 2175$2178,2011$.

[44] U. Guller, N. Jain, S. Hervey, H. Purves, and R. Pietrobon, "Laparoscopic vs open colectomy: outcomes comparison based on large nationwide databases," Archives of Surgery, vol. 138, no. 11, pp. 1179-1186, 2003.

[45] S. R. Steele, T. A. Brown, R. M. Rush, and M. J. Martin, "Laparoscopic vs open colectomy for colon cancer: results from a large nationwide population-based analysis," Journal of Gastrointestinal Surgery, vol. 12, no. 3, pp. 583-591, 2008. 


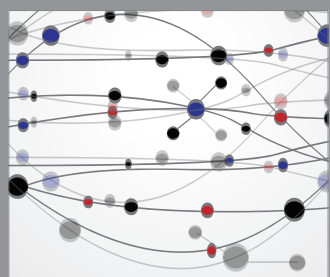

The Scientific World Journal
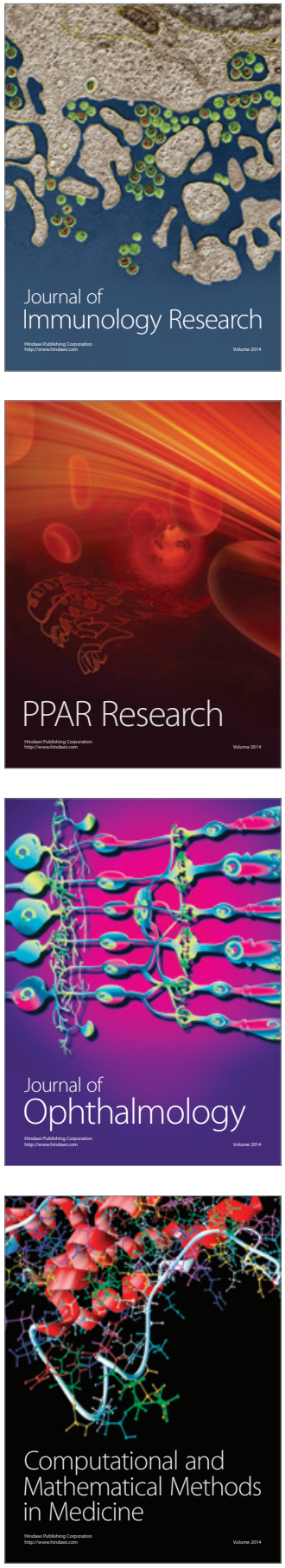

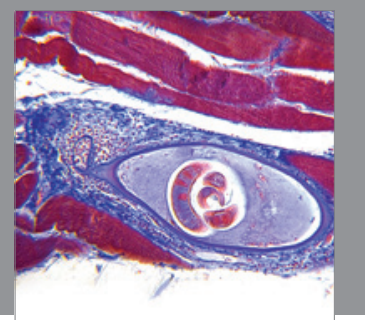

Gastroenterology

Research and Practice
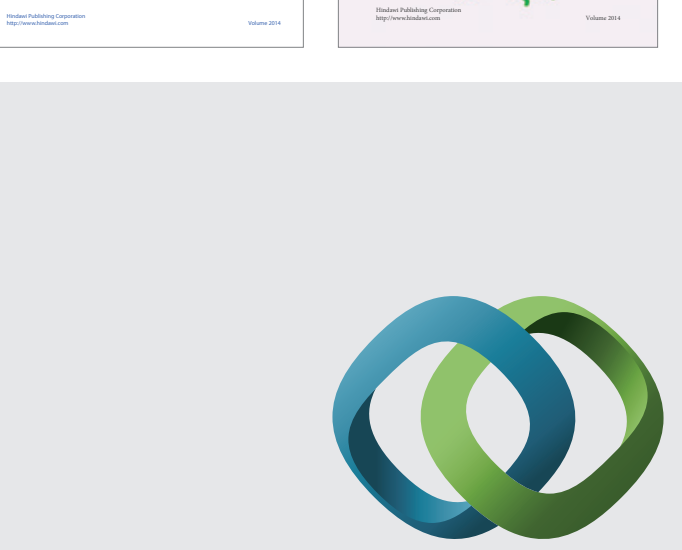

\section{Hindawi}

Submit your manuscripts at

http://www.hindawi.com
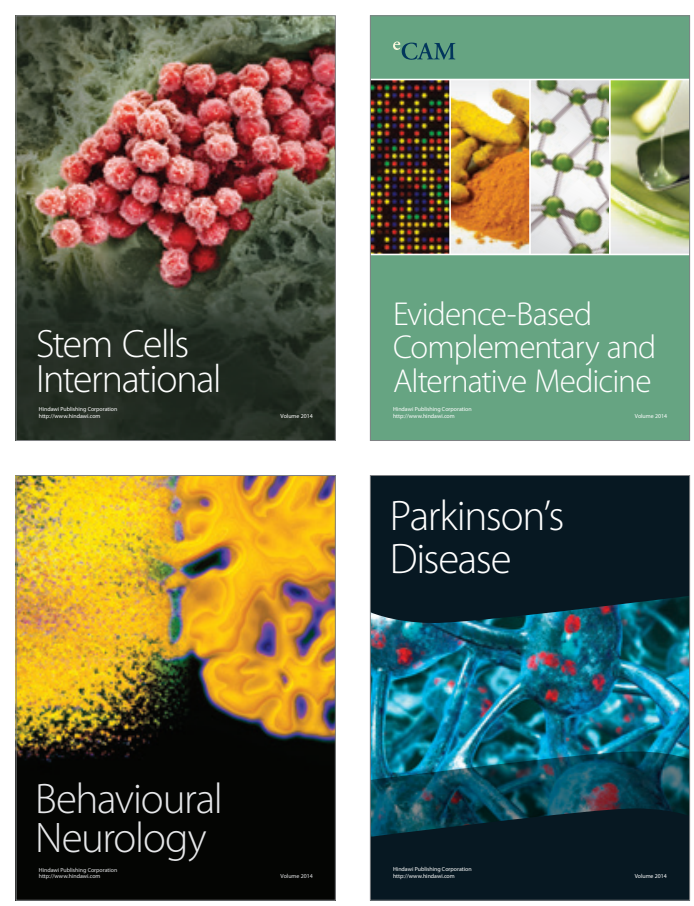

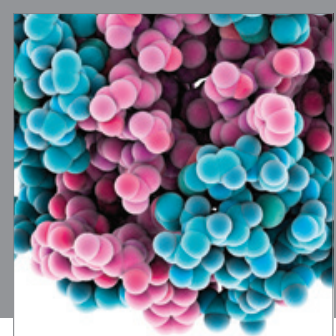

Journal of
Diabetes Research

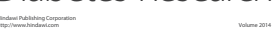

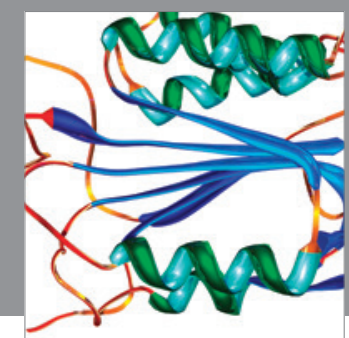

Disease Markers
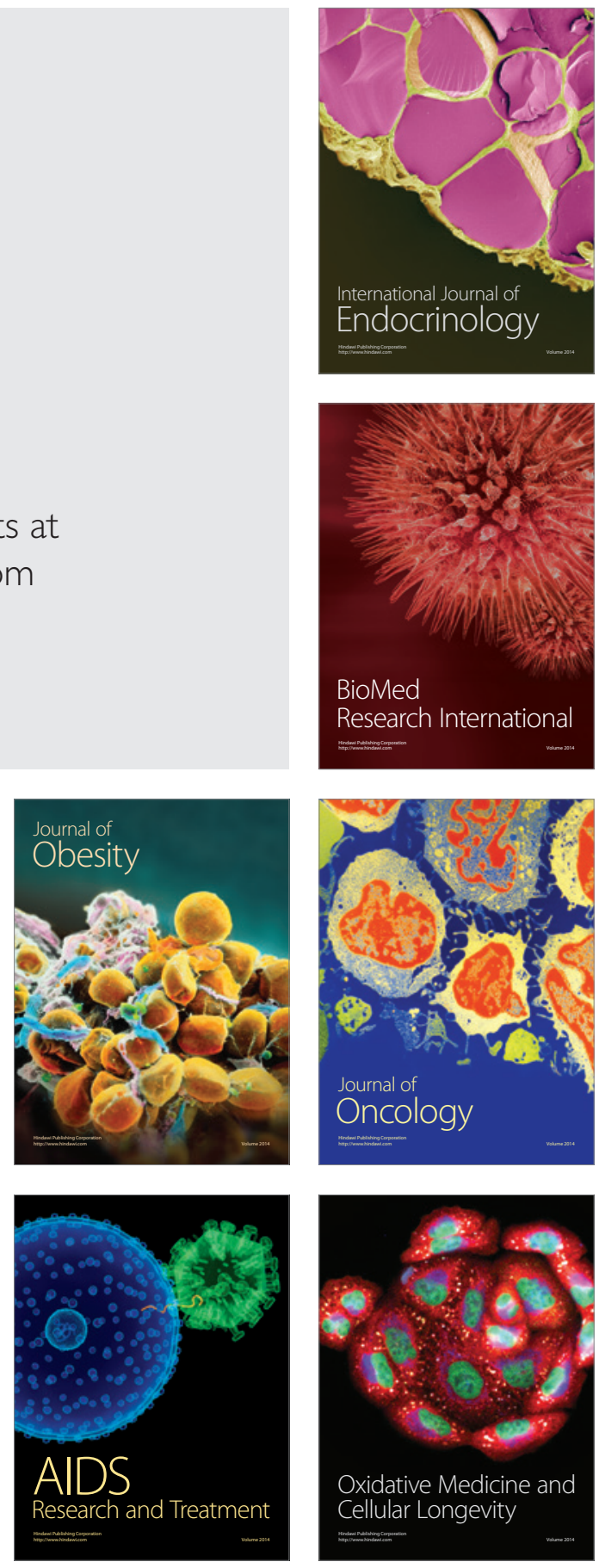